\title{
Aerial roots of orchids: the velamen radicum as a porous material for efficient imbibition of water
}

\author{
Frank Hauber $^{1} \cdot$ Wilfried Konrad $^{1,2}\left(\mathbb{D} \cdot\right.$ Anita Roth-Nebelsick $^{3}$
}

Received: 27 June 2020 / Accepted: 1 October 2020

(c) The Author(s) 2020

\begin{abstract}
Aerial roots of orchids are able to absorb atmospheric water (e.g. rain, mist, dew) and to conduct it to the root interior. The water is absorbed by imbibition into a biological porous material, the velamen radicum, which envelops the aerial root and comprises one or two to several layers. The velamen radicum consists of walls of dead cells and shows an intricate structure. In this contribution, the imbibition process was studied in more detail using mathematical principles and by experimental observation of eight orchid species. The process of absorption can be subdivided into two stages. The initial stage is the attachment of a drop to the rough surface. The drop is then imbibed into the layers of the velamen radicum. During imbibition, the contact angle decreases, because the drop remains firmly pinned to the surface. Imbibition times vary widely, due to differences in the porous structure of the considered species. It could, however, be demonstrated that a detailed theoretical study of imbibition for this complex biological material is possible using structural parameters obtained from microscope images. A third aspect which was considered was evaporation out of the velamen radicum. Also here, observations were consistent with modeling results. The velamen radicum, and other tissues involved in water absorption by aerial roots of orchids, represents an intriguing biological material for studying imbibition and flow in porous materials and has probably a high potential for discovering technically interesting features.
\end{abstract}

Keywords Imbibition $\cdot$ Contact angle $\cdot$ Porous material $\cdot$ Porous surface $\cdot$ Evaporation $\cdot$ Aerial root $\cdot$ Velamen radicum

\section{Aerial roots-structure and functions}

Electronic supplementary material The online version of this article (https://doi.org/10.1007/s00339-020-04047-7) contains supplementary material, which is available to authorized users.

Wilfried Konrad

wilfried.konrad@uni-tuebingen.de

Frank Hauber

f.hauber@student.uni-tuebingen.de

Anita Roth-Nebelsick

anita.rothnebelsick@smns-bw.de

1 Department of Geosciences, University of Tübingen, Hölderlinstrasse 12, 72074 Tübingen, Germany

2 Institute of Biology, Technical University of Dresden, Zellescher Weg 20b, 01217 Dresden, Germany

3 State Museum of Natural History Stuttgart, Rosenstein 1, 70191 Stuttgart, Germany
This contribution deals with an intricate and multifunctional porous material that has essential and vital functions in certain plants. The investigated biological material is in fact a quite common sight: it envelops the thick and fleshy roots of orchids which are also popular as houseplants. Like in "normal" roots, these orchid roots absorb water but in a remarkable way, by imbibition into a complex multilayered porous tissue. Wetting of and imbibition by porous materials is of considerable interest with respect to many technical applications, such as inkjet printing, dying and impregnation of textiles and other porous materials, penetration of water into building materials, and many more $[1,2]$. To understand the fascinating properties of this porous envelope which is termed "velamen radicum", it is necessary to first (and briefly) describe the underlying biology before considering the physical basis of its functionality.

Plants require-as all living organisms-a sufficient water supply to maintain vital functions. Usually, plants are supplied with soil water absorbed by their root system which 
also provides anchorage and contributes to mechanical stabilization. There is, however, a special ecological niche which is not compatible with soil water uptake: epiphytism which means that plants live on other plants [3]. Plants colonizing other plants are termed epiphytes. There is a high diversity of epiphytes, including mosses, ferns, and also "higher" plants, such as various orchids and Bromeliaceae (the pineapple belongs to this group). Living as an epiphyte on trees has the strong advantage of being high up in the canopy and therefore close to or within a well-illuminated region, far away from the shady ground of a forest, without the need to invest in expensive stabilizing tissues which are required to build tree trunks. There is, however, a major problem: usually, there is no contact to the soil and therefore no supply with soil water. Rather, epiphytes have to take up water directly from the atmosphere, in the form of rain, mist, fog, and also dew. The specific ecological niche of epiphytes instigated the evolution of a large number of special tissues and strategies to handle these different kinds of atmospheric water.

Epiphytic orchids are equipped with roots which have no contact to the soil, but hang more or less freely in the air. These special roots, termed aerial roots, are capable of absorbing moisture from the air. Aerial roots of orchids show distinct outer layers which separate the living root cells, mostly belonging to the cortex, from the air. The basic structure of an aerial root is shown in Fig. 1. Cortex (root ground tissue), central vascular bundle (long-distance transport of water and nutrients), and the endodermis (controlling flow of water and nutrients between cortex and vascular bundle) are also present in "normal" roots. The outer layer, termed velamen radicum which covers the exodermis, is, however, characteristic for aerial roots of orchids (but is also present in the Araceae group-as, for example, in the popular houseplant Monstera deliciosa). The velamen radicum encloses the root completely and consists mostly of several layers of dead cells (in some orchids, there are only one or two layers of velamen radicum cells). In the following, we will focus on the velamen radicum as a special biological porous material.

\section{The velamen radicum-combining efficient imbibition with reduced evaporation}

The velamen radicum has an intricate structure (Fig. 2). Since the living content of the velamen radicum cells is no longer present, the cells consist of their cell walls only which are perforated in a quite complex and species-specific manner. The velamen radicum therefore represents a highly porous medium with porosity on different levels: the larger voids occupying the cell interior and the smaller pores perforating the cell walls. Shape, length, and arrangement of the velamen cells add more spatial characteristics to the entire porous structure. As is quite obvious from Fig. 3, the velamen radicum is an anisotropic porous material. It is able to soak up atmospheric water (together with dissolved nutrients) which is then available for absorption into the living cortex [3-5]. In the dry state, the velamen radicum shows a whitish-silvery appearance, due to total reflexion caused by air filling the dead cells. Upon wetting, aerial roots of orchids usually become green, revealing the existence of chloroplasts inside the living cortex cells.

The water filling the velamen radicum is, however, not directly conducted into the cortex. Another layer, the exodermis, separates velamen radicum and cortex (Fig. 1). The
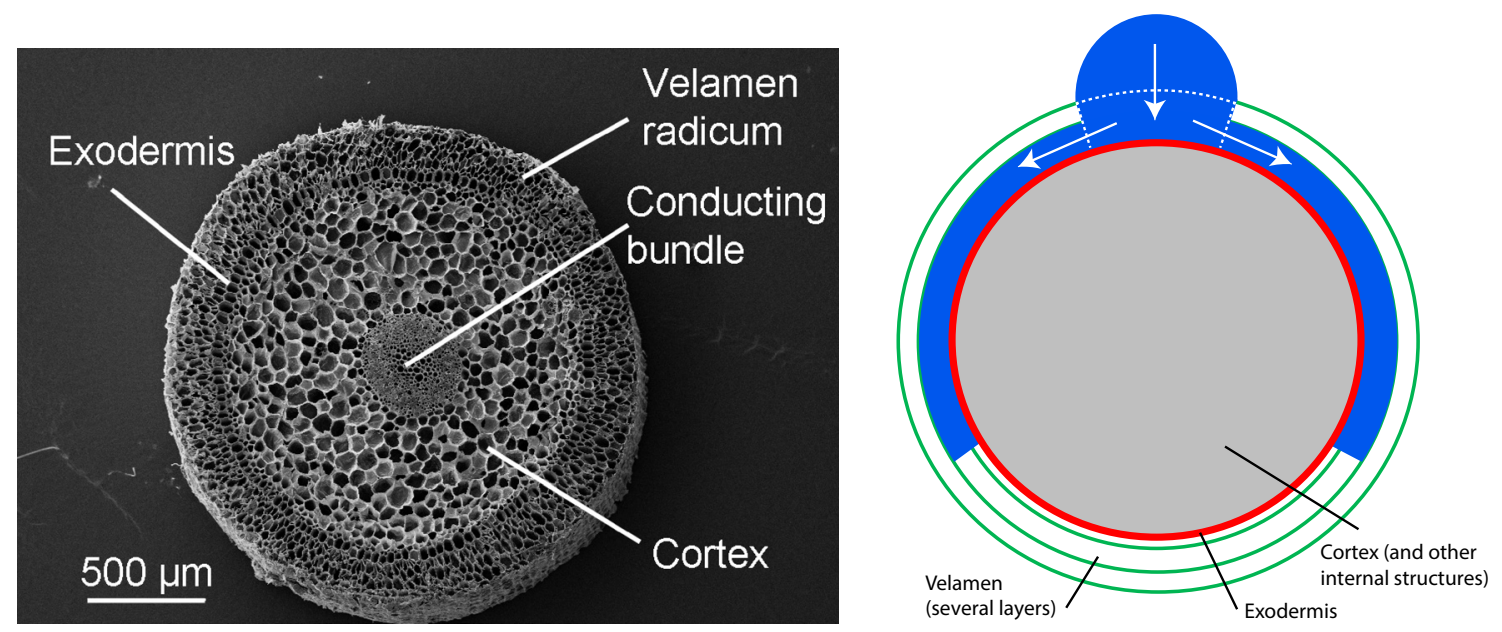

Fig. 1 Left: Basic structure of an aerial root. Scanning electron microscope (SEM) picture showing a cross section through an aerial root of Dendrobium nobile. Right: Three stages of water capture by the velamen radicum. (i) A droplet attaches to the velamen surface, (ii) occupying a certain area of the velamen (indicated by the dashed white lines). (iii) The water is imbibed into the layers of the velamen. White arrows indicate the flow direction of liquid water 

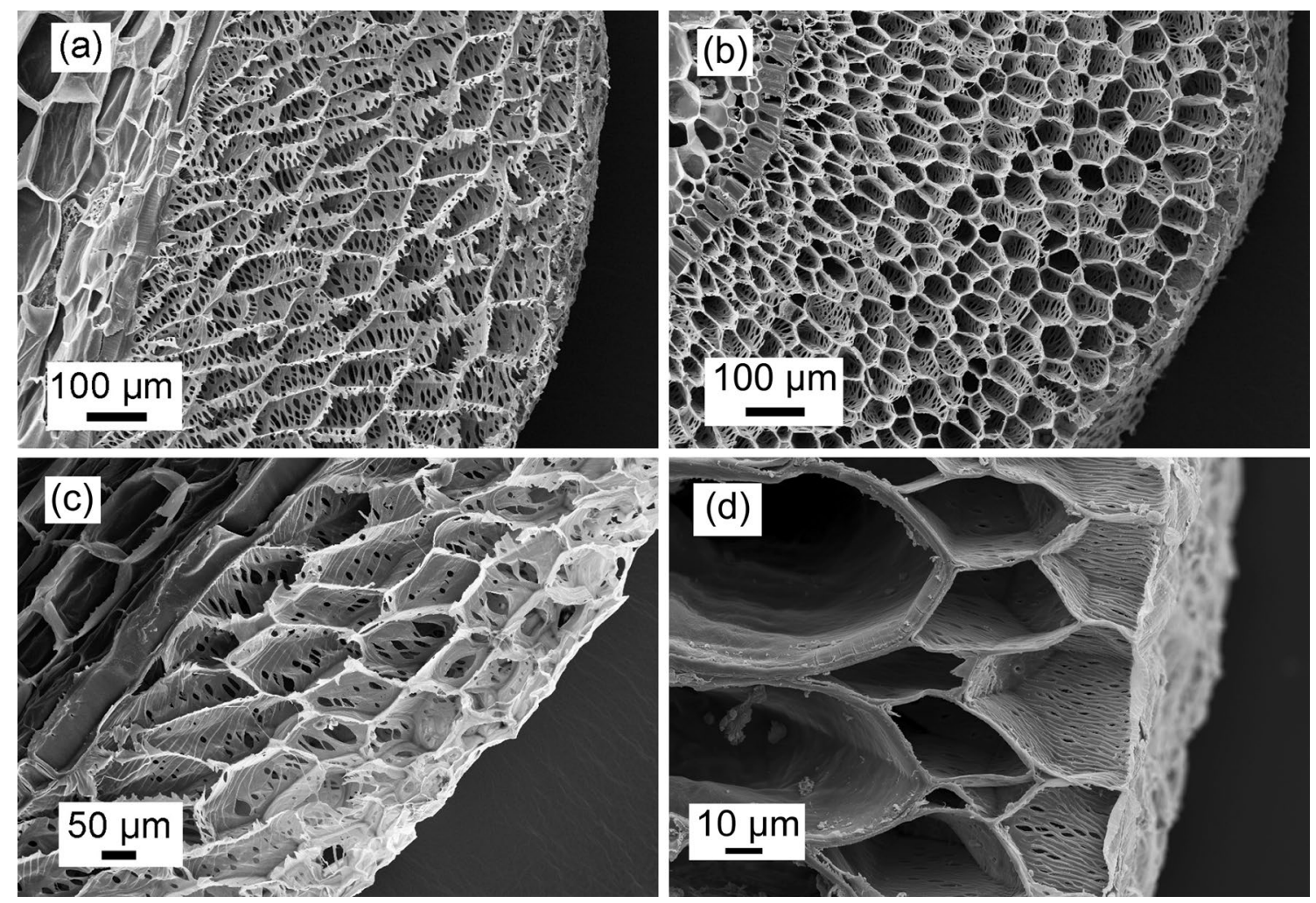

Fig. 2 SEM images of sections through aerial roots of different species, showing the velamen radicum. a Dendrobium densiflorum, longitudinal section. b Dendrobium nobile, cross section. c Dendrobium nobile, longitudinal section. d Microcoelia exilis, cross section
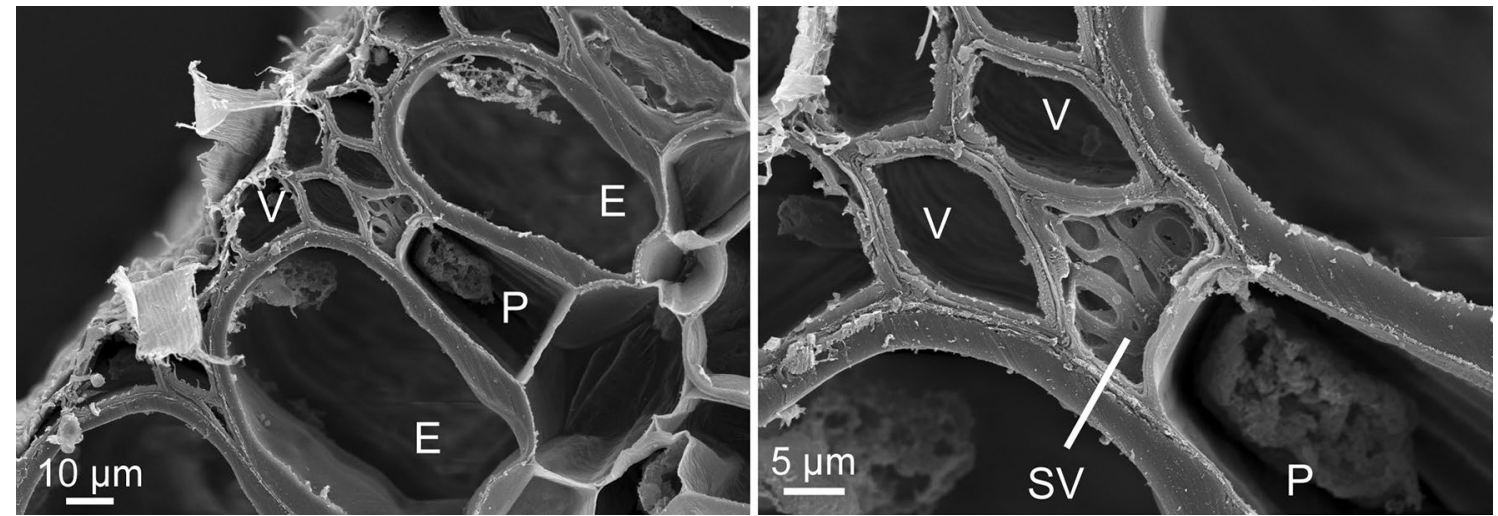

Fig. 3 SEM images of a passage cell of Microcoelia exilis, in cross section. Left: Passage cell (P) between exodermis cells (E) and topped by cells of the velamen radicum (V). Right: Special cell (SV) of the velamen radicum adjacent to a passage cell

exodermis consists mostly of dead cells whose cell walls are partially impregnated with water-repellent substances on the outside (directed to the exterior) and the walls between cells. The exodermis therefore isolates the cortex from the exterior and also from the velamen radicum. But how then can water be conducted into the cortex?

The exodermis does not consist of dead cells only but contains special passage cells which are the interface between the water reservoir inside the velamen radicum and the living cortex cells (Fig. 3). Water uptake is controlled by the living content of the passage cells and represents a physiological process. There is, however, more structural detail to this interface. Directly above the passage cells, a patch of obviously special material can be found in many species (Fig. 3). These structures show a high variety, from the so-called "tilosomes" [6] which are spongelike, fibrous, 
or spherical bodies, to other intricate patterns (as shown in Fig. 3). This material is formed by outgrowths of the inner walls of the velamen cell which is situated next to the passage cell. The living cells of the aerial root are therefore enveloped by two different layers: the innermost layer, the exodermis, which is "watertight" with the exception of passage cells controlling the water absorption, and the velamen radicum, a multilayered material with porosity on different levels, including particularly densely porous patches above passage cells.

In summary, the velamen radicum is a porous material which absorbs atmospheric water by imbibition which is then subsequently absorbed by the living passage cells. Consequently, the passage cells cannot be isolated from the velamen radicum by cell-wall impregnation as the other exodermis cells. This bears the problem that water can principally also move into the other direction when the gradient reverses after the velamen radicum has been emptied and the exodermis is in direct contact with air. The sites of water supply would become the sites of water loss, with the threat of complete dehydration which would be lethal for the plant.

Furthermore, also evaporation from the velamen radicum is critical for the plant, because water escaping from this "intermediate water storage" means that less water is available for absorption [7]. The velamen radicum should therefore be able to, first, imbibe water efficiently and, second, prevent evaporation [7]. In fact, there is evidence that the structure of the velamen affects not only imbibition but also water loss by evaporation, as noted by [3].

The outer layers of the aerial root have therefore to fulfill two demands: to swiftly imbibe external (atmospheric) water and to prevent the evaporation of internal water. This is the opposite of what is expected from those breathable clothing material which were devised to, first, prevent external water from soaking the material and reaching the skin and, second, to allow sweat to evaporate out of the textile.

In the following, it will be described how the structure of the velamen radicum is essential in fulfilling these tasks. For this study, eight different species of orchids were considered.

\section{Theoretical basis}

\subsection{The velamen water capture scenario}

The structure and the various functions of the velamen radicum suggest that plants bearing such a structure show a water capture scenario that is based on the following sequence of events (Fig. 1).

1. A droplet of water hits the velamen and remains attached to the surface. In the following, we will focus on the interaction between drops and the aerial root, because atmospheric water will be present in the form of drops (including water dripping from overhanging branches and twigs). What we will not consider are additional effects from drop impact. Rather, the analysis starts when a drop has settled on the surface.

2. Capillary forces suck the droplet first into the velamen layer close to the droplet base and conduct it then towards the lower layers of the velamen, adjacent to the passage cells. The imbibed water spreads swiftly along the velamen radicum.

3. The redistribution of the droplet water within the velamen during the imbibition process increases the water/ air interface and therefore the potential loss of water by vaporisation before it is absorbed into the root interior beyond the exodermis. It is proposed that this evaporative water loss is minimized by the velamen radicum.

In what follows we first describe the theoretical basis of the analysis, followed by the presentation and discussion of experimental results that quantify this scenario. We will show that the application of simple mathematical models allows to estimate typical time scales related to these processes.

\subsection{Formation of a sessile droplet}

Assume that the surface of the velamen radicum comes into contact with a water drop. To catch the drop, the surface must not be water repellent. Rather, the drop should attach to the surface and spread until a final equilibrium contact angle is attained. Plant cell walls consist mainly of cellulose and so do the cell walls of the velamen radicum. Cellulose is hydrophilic, but the walls of velamen radicum cells also contain lignin which is hydrophobic [8]. Direct measurements of lignified cell walls indicate an average contact angle of about $50^{\circ}$, but also substantially higher contact angles can occur [9].

Furthermore, the behavior of the drop will be substantially affected by the porous nature of the surface. The surface of a porous non-hydrophobic material will start to imbibe water as soon as the drop is placed. Since drop size exceeds surface roughness typically by two orders of magnitude (Fig. 4) the drop will rest upon a patchwork of solid and liquid (i.e., the water already filling the pores). The apparent contact angle depends in this case on the interrelationships between roughness structure, imbibition strength and wetting front and will be significantly larger than for an impermeable surface consisting of the same material [10]. 

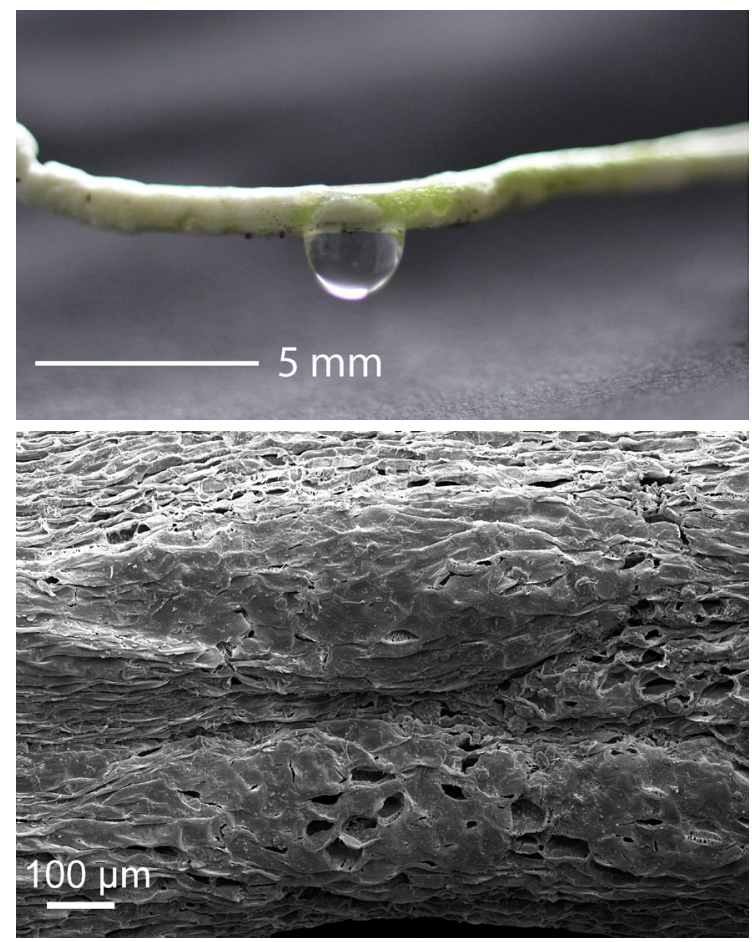

Fig. 4 Contact angle and surface of the velamen radicum. Upper left: Droplet hanging from the aerial root of Dendrobium nobile. Upper right: Droplet sitting on the aerial root of Microcoelia exilis. Lower left: SEM image of the surface of the velamen radicum of Microcoelia exilis. Lower right: Contact angle for dry aerial roots of eight species, shown as Box-Whisker plots. The "whiskers" span between

\subsection{Imbibition}

Once the droplet has settled on the surface of the velamen, two competing processes shrinking the droplet volume are initiated: imbibition of the droplet into the velamen and evaporation of the droplet into the surrounding air. Clearly, an accurate quantitative model should include both mechanisms. This would be, however, quite complex with respect to mathematics. In the following, we use a simple model of droplet evaporation which is, however, sufficient for the purpose of this study. The model, outlined in appendix A, estimates evaporation time in the absence of imbibition, with the result:

$t=\frac{s^{2}}{4 \sqrt{2} D V_{\mathrm{m}}\left(w_{\mathrm{sat}}-w_{\mathrm{a}}\right)}\left[\operatorname{artanh}\left(\sin \left(\gamma_{0} / 2\right)\right)+\frac{\sin \left(\gamma_{0} / 2\right)}{\cos ^{2}\left(\gamma_{0} / 2\right)}\right] ;$

$s$ denotes the radius of the contact line of the water droplet, $D$ is the coefficient of diffusion of water vapor in air, $V_{\mathrm{m}}$ is the molar volume of liquid water, $w_{\text {sat }}$ and $w_{\mathrm{a}}$ denote the humidities at the water/air interface and at infinity, respectively, and $\gamma_{0}$ is the contact angle that forms initially between water and velamen.
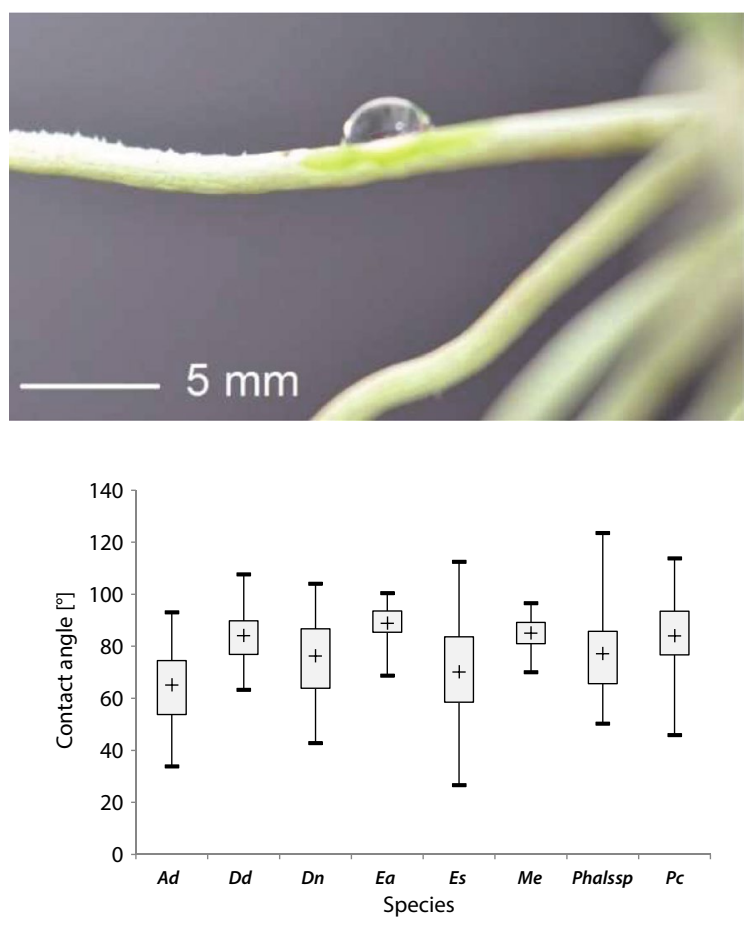

the minimum and maximum values. The cross indicates the median value. Considered species: Ad Angraecum didieri, Dd Dendrobium densiflorum, Dn Dendrobium nobile, Ea Encyclia adenocarpa, Es Epidendrum secundum, Me Microcoelia exilis, Phalssp. Phalaenopsis ssp., and Pc Prosthechea cochleata

The driving force of imbibition is the capillary pressure. The Young-Laplace equation:

$p_{\mathrm{c}}=\frac{2 \sigma}{r_{\mathrm{c}}}$

expresses $p_{\mathrm{c}}$ in terms of properties of the fluid (the surface tension $\sigma$ ) and structural properties of the velamen: $r_{\mathrm{c}}$ denotes the radius of curvature of the water/air meniscus of a water column filling (partially) a pore.

If such a void (Fig. 5) is (at least approximately) shaped like a circular tube of (constant) radius $b$, the quantity $r_{\mathrm{c}}$ can be expressed as $r_{\mathrm{c}}=b / \cos \gamma$ and relation (2) reads:

$p_{\mathrm{c}}=\frac{2 \sigma \cos \gamma}{b}$.

For hydrophilic materials (Fig. 5a), the contact angle is in the range $0 \leq \gamma<90^{\circ}$ and $p_{\mathrm{c}}$ is positive. In this case, a concave meniscus forms that draws the water front forward into hitherto air-filled domains. A hydrophobic wall material, in contrast, yields a convex meniscus which is associated with $90^{\circ}<\gamma \leq 180^{\circ}, p_{c}$ is then negative, and the water front is rather pushed back (Fig. 5b). If the velamen would consist of a multitude of parallel oriented tubes with constant radii, the 


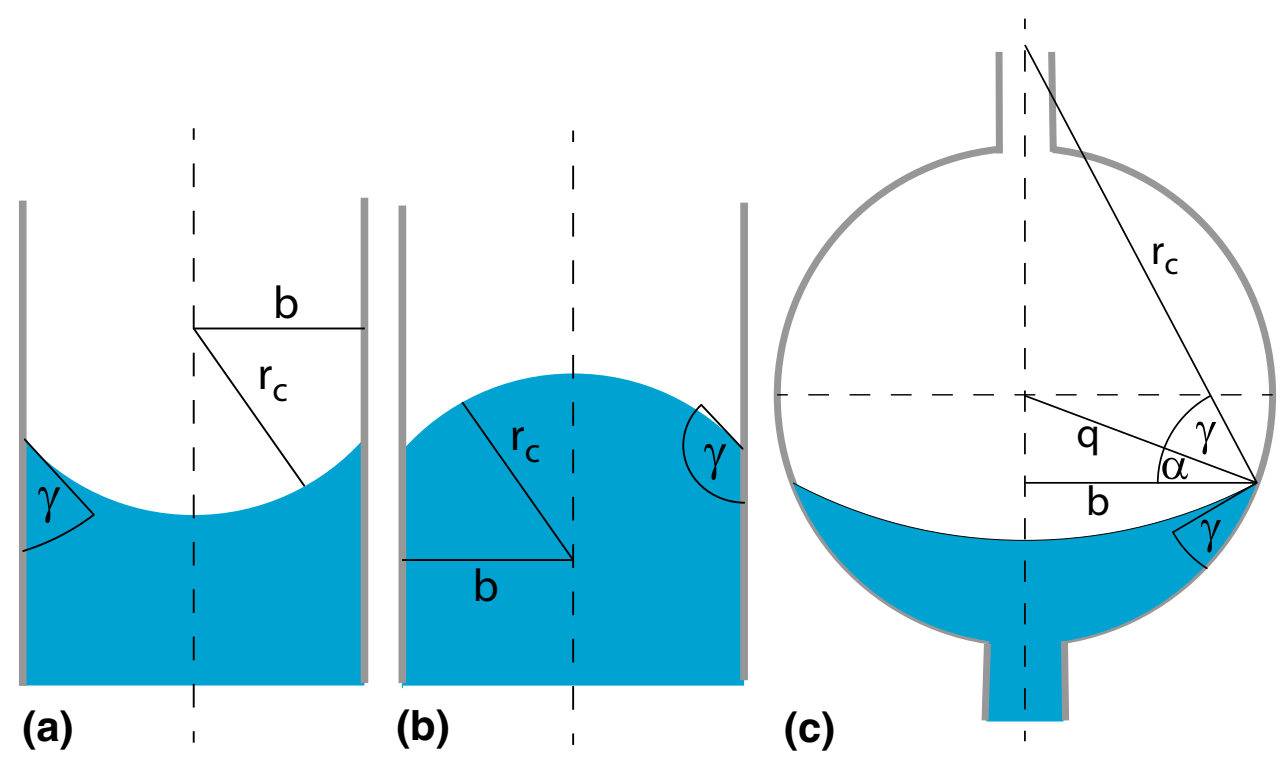

Fig. 5 Left and centre: In a cylindrical tube of radius $b$ forms a water/air interface of curvature radius $r_{\mathrm{c}}$. For a hydrophilic material $\left(\gamma<90^{\circ}\right.$, left), a concave interface forms; for a hydrophobic material $\left(90^{\circ}<\gamma<180^{\circ}\right.$, centre), the interface is convex. Right: The curvature of a water/air interface that forms in a sphere depends on the position of the interface (defined by the angle $\alpha$ ) and on the contact angle $\gamma$ between water (blue) and air (white): The interface that forms is convex if the water level is close to the lower end of the sphere,

value of the contact angle alone would determine whether the meniscus is concave or convex; that is, whether the capillary pressure draws the meniscus forward (as in Fig. 5a) or pushes it back (as in Fig. 5b), respectively.

However, according to Fig. 2, the velamen structure comprises all sorts of obliquely shaped geometric objects, whereas circular pores of constant radii seem not to occur. This complicates the approach, because in such cases, the combination of contact angle and pore geometry decides if a concave or a convex meniscus develops. Figure $5 \mathrm{c}$ illustrates the situation. Here, the cell is not approximated as a cylinder, as in Fig. 5a, b but-somewhat more realistic-as a sphere. For what follows, let us assume that water enters from below and rises upwards. The position of the water front can be marked by the distance $b=0 \ldots q$ between the symmetry axis of the arrangement and the contact line where water air and solid meet ( $q$ is the radius of the sphere) or, equivalently, by the angle $\alpha=-\pi / 2 \ldots \pi / 2$.

Clearly, $r_{\mathrm{c}}$, the radius of curvature of the air/water meniscus varies if the water front proceeds within the cell (provided that the contact angle $\gamma$ remains constant). Applying the definition of the cosine, one finds $\cos \alpha=b / q$ and $\cos (\alpha+\gamma)=b / r_{\mathrm{c}}$. Eliminating $b$ from these relations and insertion into (2) lead to: becomes flat if the water has risen to a level where the condition $\alpha+\gamma=90^{\circ}$ applies, and becomes finally concave if the water level approaches the upper end of the sphere. Where the flat episode occurs depends on the wall material: if it is neither hydrophilic nor hydrophobic (that is, $\gamma=90^{\circ}$ ), the water surface becomes flat exactly halfway between upper and lower end of the sphere, for hydrophilic wall material this occurs in the lower half of the sphere, and for hydrophobic material in the upper half of the sphere

$p_{\mathrm{c}}=\frac{2 \sigma}{q} \frac{\cos (\alpha+\gamma)}{\cos \alpha}=\frac{2 \sigma}{q}(\cos \gamma-\sin \gamma \tan \alpha)$,

where the addition theorem for the cosine has been used in the last step. Thus, both sign and value of the capillary pressure $p_{\mathrm{c}}$ depend on the position of the meniscus, represented by $\alpha$, within the cell. Since the water front moves simultaneously through many cells, the related menisci will adopt many different positions with respect to their cells at the same time. This suggests to use the mean value of (4) with respect to position, namely:

$\overline{p_{\mathrm{c}}}=\frac{1}{\pi} \int_{-\pi / 2}^{\pi / 2} p_{\mathrm{c}}(\alpha) d \alpha=\frac{2 \sigma}{q}\left(\cos \gamma-\frac{\sin \gamma}{\pi} f_{-\pi / 2}^{\pi / 2} \tan \alpha d \alpha\right)$.

The integral vanishes, because $\tan \alpha$ is an antisymmetric function with respect to $\alpha=0$ and the integration extends over an interval that is symmetric with respect to $\alpha=0$. (The singularities at $\alpha=-\pi / 2$ and $\alpha=\pi / 2$ cancel on the understanding that the integral represents the principal value.) Thus, we obtain finally:

$\overline{p_{\mathrm{c}}}=\frac{2 \sigma \cos \gamma}{q}$, 
for the mean capillary pressure. Obviously, if the radius $q$ of the sphere (Fig. 5c) and the radius $b$ of the straight tube (Fig. 5a,b) coincide, expression (3) and the more sophisticated expression (6) produce the same result.

\subsection{Fluid flow in porous media}

The flow of a liquid through a porous medium whose structure is not given in detail can be described by Darcy's Law:

$Q=-A \frac{k}{\mu} \operatorname{grad} p$,

where $Q$ is the volume of liquid flowing per time across the area $A$ (oriented normally with respect to the direction of $Q$ ). The driving force is provided by the pressure gradient (here, essentially, the gradient of the capillary pressure $p_{\mathrm{c}}$ ), and the fraction $k / \mu$ represents the conductance of the medium for a given liquid: $k$ is the permeability of the porous medium; $\mu$ is the dynamic viscosity of the fluid.

Further on, we simplify the actual water movement within the velamen by splitting it up into two stages: At first (stage one), water from the droplet is sucked into the velamen into a normal direction with respect to the velamen surface and the water front moves towards the exodermis which represents the inner boundary of the velamen. Since the exodermis has a far lower permeability than the velamen, the water front has to change its direction once it strikes the exodermis and moves then (stage two) laterally in all directions, parallel to the exodermis. We are particularly interested in the time scales on which the water fronts advance within the velamen during these two stages. The relations describing this can be deduced from (7), resulting in two versions of the Washburn equation which will be derived in what follows.

- Assuming a laminar flow regime, the movement of a water front in a capillary of constant cross section $A$ is obtained using $\operatorname{grad} p=\partial p / \partial z$ in (7) and integrating. The initial condition $p\left(z_{0}\right)=p_{0}$ at $z=0$ leads to:

$\frac{Q}{A} z=-\frac{k}{\mu}\left(p-p_{0}\right)$.

Using the relation $Q / A=\phi(\mathrm{d} z / \mathrm{d} t)$ (where $\phi$ is the porosity of the velamen) in (8), integration along the water column within in the capillary (with initial condition $z=0$ at $t=0$ ) results in the relation:

$Z^{2}=\left(\frac{2 k p_{\mathrm{c}}}{\mu \phi}\right) t$

describing the advancement of the water front, characterised by the coordinate $Z$, and driven by the capillary pressure $p_{\mathrm{c}}=p_{0}-p$, as given in expressions (2) or (3). In our case, other forces than the capillary pressure (gravitation, for instance) can be ignored.

- During stage two, the flow of the water is restricted by the exodermis and the velamen's outer margin; that is, the water flows approximately parallel to these two surfaces (Fig. 1b). If the thickness of the velamen is small compared to the radius of the aerial root, it is justified to treat both surfaces as flat (and not cylindrically bent) and to avoid thereby mathematical complexities. Table 1 shows that the ratio of velamen thickness to root radius is not exactly small, but, once again, we are interested in orders of magnitude only.

Regarding the velamen space between outer margin and exodermis as flat, we have effectively an axially symmetric situation (the water flows radially away from the base of the droplet). Therefore, the Washburn approach has to be modified slightly [11]. If water may flow only radially within a disc of height $h$, the area normal to the flow direction depends on $r$ (the distance from the symmetry axis) according to $A=2 \pi r h$. Proceeding analogously as above one obtains in a first step:

$\frac{Q}{2 \pi h} \ln \left(\frac{R}{R_{0}}\right)=-\frac{k}{\mu}\left[p(R)-p\left(R_{0}\right)\right]$.

Employing $Q=A \phi(\mathrm{d} R / \mathrm{d} t)=2 \pi R h \phi(\mathrm{d} R / \mathrm{d} t)$ and $p\left(R_{0}\right)-p(R)=p_{\mathrm{c}}$ yields, with the initial condition $R=R_{0}$ at $t=0$ :

$\int_{R_{0}}^{R} R \ln \left(\frac{R}{R_{0}}\right) \mathrm{d} R=\frac{k p_{\mathrm{c}}}{\mu \phi} \int_{0}^{t} \mathrm{~d} t$.

Execution of the integration shows that the water front at $R(t)$ advances with time as:

$\left(\frac{R}{R_{0}}\right)^{2}\left[2 \ln \left(\frac{R}{R_{0}}\right)-1\right]+1=\left(\frac{4 k p_{\mathrm{c}}}{R_{0}^{2} \mu \phi}\right) t$.

This result allows to calculate the time it takes to imbibe a droplet of initial volume $V$ completely into the velamen.

\subsection{Evaporation from the velamen radicum: Fick's Law and the diffusion equation}

The current $I$ of gas particles (such as water vapor) whose driving force is provided by the gradient of the concentration of these particles is governed by Fick's Law:

$I=-A D \operatorname{grad} w$, 
where $w$ is the particle concentration, $D$ is the coefficient of diffusion, and $A$ is the area (oriented normally with respect to the direction of $I$ ) traversed by the particles.

If the particle pathway leads through a porous medium, $D$ should be replaced by $D_{\mathrm{e}}$, the effective coefficient of diffusion that takes the effect of obstacles into account (see expression (16), below). Before (13) can be applied the distribution of the particle concentration, $w$ has to be obtained as a solution of the diffusion equation (43) (Appendix 2). Once $I$ is known, it can be used to calculate the time it takes for a given stored volume of liquid water to evaporate from the velamen. One finds:

$$
\begin{aligned}
t= & \frac{\tau^{2} \phi}{4 V_{\mathrm{m}} D\left(w_{\mathrm{sat}}-w_{\mathrm{a}}\right) \phi_{\mathrm{a}}} \\
& \times\left(r_{0}^{2}\left[\ln \left(r_{\mathrm{a}}^{2}\right)-\ln \left(r_{0}^{2}\right)+1\right]-r_{i}^{2}\left[\ln \left(r_{\mathrm{a}}^{2}\right)-\ln \left(r_{i}^{2}\right)+1\right]\right),
\end{aligned}
$$

where $r_{\mathrm{a}}$ denotes the radius of the velamen, and $r_{0}$ and $r_{i}$ are the positions of the water/air interface at $t=0$ and after the time span $t$, respectively. The structure of (14)) implies that the time span $t$ required for the complete evaporation of the imbibed water depends strongly on the atmospheric humidity $w_{a}$ (or rather on the difference $w_{\text {sat }}-w_{\mathrm{a}}$ ).

To apply Darcy's and Fick's laws in porous media, estimates of permeability $k$ and the effective coefficient of diffusion $D_{\mathrm{e}}$ should be known. For lack of direct measurements of these quantities for the velamen radicum, we have to rely on models that derive $k$ and $D_{\mathrm{e}}$ from anatomical traits which can be derived from scanning electron microscope (SEM) images. The literature on such models is manifold (see, e.g., [12-16]).

Most of these approaches consist of a "core" of expressions (usually including porosity and geometric quantities such as pore radius, tortuosity, etc.) whose structure is motivated by the physics of a comparable but idealised medium. The discrepancies between idealised and real structure are then taken into account by one or more additional numerical factors that have to be obtained in some way.

According to the large data scatter of the involved parameters (as is natural for a biological material, see results), we aim at rough approximations, and we will therefore use simple expressions for $k$ and $D_{\mathrm{e}}$ and do not attempt to determine the numerical factors accurately.

For permeability, we use the expression [16]:

$$
k=\frac{a^{2} \phi_{\mathrm{a}}}{c \tau^{2}} .
$$

Here, $a$ is the typical radius of the wall openings connecting adjacent velamen cells, $\phi_{\mathrm{a}}$ denotes the porosity of these walls, and $c$ is a geometric factor that accounts for the shape and connectivity of the pores. Typically, $c$ is in the range $c=1 \ldots 10 . \tau=l_{e} / l$ is tortuosity: $l$ denotes the geometric distance between two points, while $l_{e}$ denotes the effective length of the diffusional pathway between them. If a particle goes round an obstacle in a half-circle, the tortuosity of this bypass amounts to $\pi / 2$.

For the effective coefficient of diffusion in porous media, we use the suitable and customary expression:

$D_{\mathrm{e}}=D \frac{\phi_{\mathrm{a}}}{\tau^{2}}:$

$D$ denotes the coefficient of diffusion in free air, and $\phi_{\mathrm{a}}$ and $\tau$ are defined as in the case of permeability.

\section{Results}

In the following, the above considerations and models will be applied to imbibition into the velamen radicum. For this, various data collected on eight species (for measured data, see the Online Resource) will be used to evaluate the imbibition process and its interrelationships with the biological structure. Finally, it will be attempted to calculate imbibition characteristics for two exemplary species.

\subsection{Droplet formation}

The outer surface of the velamen shows quite irregular and species-specific roughnesses (Fig. 4) which substantially affect the apparent contact angle (Fig. 4). This highly rough surface is probably the reason for the high scatter of the contact angle data and leads also to the observed fast pinning of a drop. For the considered species, the contact angles amount on average to about $70^{\circ}-80^{\circ}$. This mean contact angle is close to the contact angle values obtained by Clarke et al. [17] for microporous membranes based on cellulose esters. Furthermore, rapid pinning was observed for all velamen radicum surfaces of the considered species..

\subsection{Imbibition}

Comparison of droplet life-times predicted by expressions (1) and (40) (Figs. 10 and 11, respectively) with observations of imbibition velocity (Fig. 9 and Table 1 ) reveals that droplets subjected merely to evaporation disappear about one order of magnitude later than droplets subjected also to imbibition. This justifies to disregard evaporation in (approximative) models of imbibition by velamen structures.

Due to the rapid and strong pinning, the drop contact line (Fig. 8 and $[10,18]$ ) remained fixed for all considered species, as observed in all our experiments. This has the 
consequence that the initial equilibrium contact angle steadily decreases during imbibition (cf. Fig. 11), also in agreement with the observations of Clarke et al. [17]. With respect to imbibition velocity, considerable and partially significant differences exist between the considered species whose roots completely absorb the drop between several seconds $(<10 s)$ and more than $2 \mathrm{~h}(\approx 8000 \mathrm{~s})$, with a rough average for all absorption times of about 200s (Fig. 9). Also, the imbibition times vary considerably between species.

We will now compare model predictions and observations along the velamen water capture scenario outlined in Sect. 3.1 (Fig. 1b), concentrating on the species Dendrobium nobile and Microcoelia exili (Fig. 2).

Equation (9), together with (6) and (15), allows to calculate the time it takes a water front starting from the base of the droplet settled on the velamen to reach the exodermis, at a distance $Z$ (big white arrow in Fig. 1):

$t=\left(\frac{\mu \phi}{2 k p_{c}}\right) Z^{2}=\left(\frac{\mu c \tau^{2} q \phi}{4 \sigma a^{2} \cos \gamma \phi_{a}}\right) Z^{2}$.

Employing $c=1$ and the numerical values of Table 1 in expression (17) yields:

$t=0.15 \mathrm{~s}(D$. nobile $) \quad$ and $\quad t=0.05 \mathrm{~s}$ (M. exilis).

When the water front has reached the exodermis, it begins to flow along the exodermis (smaller white arrows in Fig. 1). Imbibition is completed when the whole droplet has been sucked into the velamen. The droplet occupies then a disc of thickness $H$, radius $R_{\mathrm{m}}$ and volume $\pi R_{\mathrm{m}}^{2} H \phi=V(V$ denotes the initial droplet volume), implying that:

$R_{\mathrm{m}}=\sqrt{\frac{V}{\pi H \phi}}$.

The time span related to these water movements can be calculated by inserting expressions (6), and (15), and (19) into Eq. (12), resulting in:

$t=\left\{\left(\frac{V}{\pi H \phi R_{0}^{2}}\right)\left[\ln \left(\frac{V}{\pi H \phi R_{0}^{2}}\right)-1\right]+1\right\}\left(\frac{\mu R_{0}^{2} c q \tau^{2} \phi}{8 \sigma \cos \gamma a^{2} \phi_{a}}\right)$.

With the numerical values of Table 1 and $c=1$, calculation of imbibition time for the two species (via (20)) gives:

D. nobile: $t_{\text {calc }}=c 24 \mathrm{~s}=24 \mathrm{~s}$

M. exilis: $t_{\text {calc }}=c 4979 \mathrm{~s}=4979 \mathrm{~s}$.

The observed imbibition times (Fig. 9, Table 1) amount to:

D. nobile: $t_{\mathrm{obs}}=45 \mathrm{~s} \quad(5 \mathrm{~s}-155 \mathrm{~s})$

M. exilis: $t_{\mathrm{obs}}=507 \mathrm{~s} \quad(55 \mathrm{~s}-2385 \mathrm{~s})$, where the values in parenthesis indicate the range of observations. Calculated values and observed values show similar trends, with $D$. nobile: showing a faster imbibition in both data sets compared to M. exilis:. However, calculated results for M. exilis are higher than the observed data, even when the large range of the latter ones are taken into account (the ratio [maximum time/minimum time] amounts to 31 for $D$. nobile, and to 43 in the case of M. exilis). Comparison of (22) with (21) yields the values $c=2.25$ and $c=0.10$ for the constant $c$ defined in (15). As shown by Fig. 9, all considered species show a wide spread of imbibition times among individuals.

It is to be expected that imbibition depends on the structural details of the velamen. A crucial parameter is permeability, which depends on the geometry of the pore space.

The pore structure of the surface and within the velamen radicum is quite irregular and species-specific. Surface pores of Dendrobium densiflorum, for example, show pores in the shape of a wickerwork, while the surface pores in Dendrobium nobile are round (Fig. 2). In all species, the surface is partially covered by a thin cellulosic layer which is the outer wall layer of the cells. In the youngest part of the root, the tip region, the outer cell walls are still intact. With time, the outer cell-wall layers peel off, leaving an irregular pattern of open pores to the exterior. As to expect from Fig. 4, the surface porosity varies strongly between species and mostly also within one species. Highest values amount to about $70 \%$, and also very low porosities of some few percent occur. Very low porosities are mostly due to the irregular process of peeling off of the outermost cellwall layers.

\subsection{Evaporation out of the velamen}

Finally, the aspect of evaporation out of the velamen radicum will be considered. The passage cells are scattered within the exodermis. Due to this circumstance and to the fact that water has to pass these living cells to reach the cortex, it is to be expected that this process will take some time. Therefore, the question arises, how quickly the water envelope imbibed into the velamen radicum will be evaporated, and therefore lost for the plant. This has been calculated in Appendix B, resulting in expression (14). If the velamen is completely soaked with water when evaporation starts (i.e., $r_{0}=r_{\mathrm{a}}$ at $t=0$ ) and evaporation stops when the water/air interface has receded to the exodermis (i.e., $r_{\mathrm{i}}=r_{\mathrm{a}}-Z$ ) expression (14) becomes: 


$$
\begin{aligned}
t= & \frac{\tau^{2} \phi}{4 V_{\mathrm{m}} D\left(w_{\mathrm{sat}}-w_{\mathrm{a}}\right) \phi_{\mathrm{a}}} \\
& \times\left(r_{\mathrm{a}}-Z\right)^{2}\left[\left(\frac{r_{\mathrm{a}}}{r_{\mathrm{a}}-Z}\right)^{2}-\ln \left(\frac{r_{\mathrm{a}}}{r_{\mathrm{a}}-Z}\right)^{2}-1\right] .
\end{aligned}
$$

Figure 12 indicates that typical evaporation times are in the case of $D$. nobile-in the range of a few hours. It may be presumed that not much water will be lost in this manner, because, first, air humidity should be higher when atmospheric water is available, implying via the difference $w_{\text {sat }}-w_{\mathrm{a}}$ in the denominator of expression (14) an increase in evaporation time. Second, observations (Fig. 9) indicate that a moist velamen radicum becomes dry well within $1 \mathrm{~h}$. For M. exilis, however, water evaporates much faster from its thin velamen radicum.

\subsection{The role of cell-wall porosity vs. overall porosity}

With respect to the pores within the interior of the velamen radicum, the basic structural unit is an elongated (dead) cell

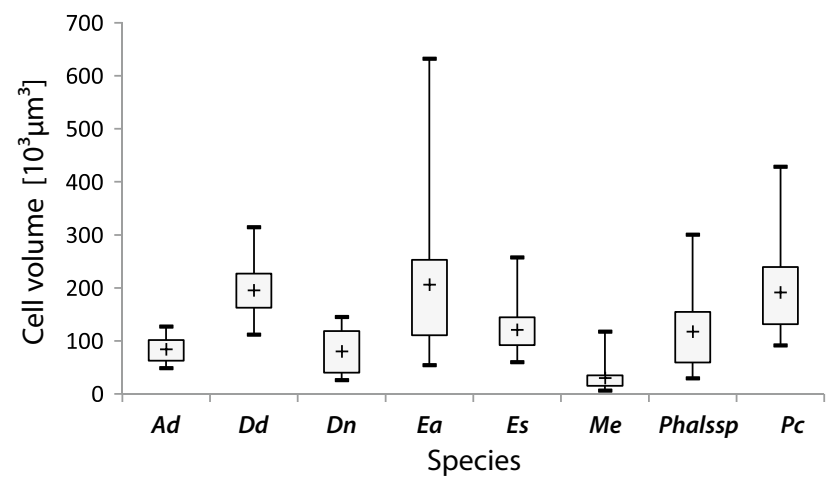

Fig. 6 Variation of cell volume between species (see species list in Fig. 4) which is mostly void. Its walls are perforated by pores connecting adjacent cells. Both the volume of velamen radicum cells and the cell-wall pore sizes vary widely, between species as well as within one species (Figs. 6 and 7). Smallest pore sizes (expressed as pore area) amount to some few $\mu \mathrm{m}^{2}$ (or even less in the species Microcoelia exilis), whereas the largest pores attain values around $1000 \mu \mathrm{m}^{2}$ in Encyclia adenocarpa, featuring huge cell-wall perforations. Since, however, the cell-wall perforations are expected to be the limiting factor for permeability, their influence on drop absorption is higher compared to cell volume. This is corroborated by the structure of expression (20) (below): the imbibition period is proportional to the ratio $q / a^{2}$; that is, variations of the radius $a$ of the wall openings affect permeability much more than variations of the cell radius $q$.

Both the imbibition times (17) and (20) and the evaporation time (14) are proportional to the term $\tau^{2} \phi / \phi_{a}$, despite the fact that (17) and (20) are related to the flow of a liquid, whereas (14) describes a flowing gas. It is intuitively clear that the tortuosity $\tau$ and the porosity $\phi_{\mathrm{a}}$ of the cell walls affect the particle pathway in liquid and gas in a very similar way: higher values of $\tau$ and lower values of $\phi_{\mathrm{a}}$ are tantamount with more obstacles that prolongate the pathways of both liquid and gas particles.

With respect to the overall porosity $\phi$ of the velamen, things are, however, different: the imbibition times (17) and (20) become extended if $\phi$ increases, because larger voids that have to be filled with water slow down the advancing water front more effectively. In contrast, the depletion of the velamen due to evaporation (described by expression (14)) is slowed down by larger voids, because they contain a larger water supply which needs a longer time to evaporate (under otherwise constant conditions). Thus, the presence of the common factor $\tau^{2} \phi / \phi_{\mathrm{a}}$ in (17), (20), and (14) reflects the fact that the water conservation mechanism of the velamen achieves its objective by
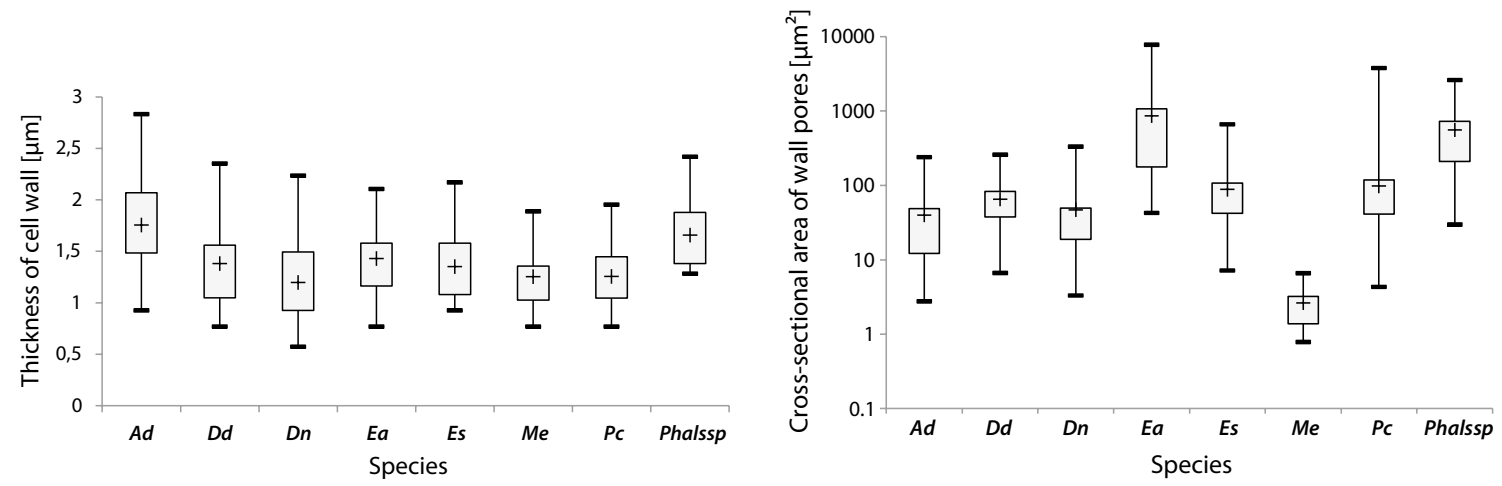

Fig. 7 Left: Thickness of cell walls (within the velamen) for several species. Right: Cross-sectional area of wall pores for several species (see species list in Fig. 4) 
utilising the same structural properties to interfere with the movements of liquid and water vapor.

The impact of porosity on evaporation is also relevant for the tilosomes and other structures situated between passage cells and velamen radicum. It is to be expected that these structures substantially affect water movement-flow of liquid water as well as diffusion of water vapor-between passage cells and velamen. For liquid water, a patch of material with much narrower pores may act as a wick. In this manner, water could be directed to the passage cells. For water vapor, however, these patches may act as evaporation reducers.

\section{Discussion and conclusions}

The velamen radicum appears to be an attractive and interesting system with respect to combining different functions. First, effective imbibition is supposed to be of vital importance for the absorption of atmospheric water, and therefore, high selective pressure should have shaped the structure of the velamen radicum to perform this function with a high performance. From an ecophysiological viewpoint, plants possessing aerial roots should particularly benefit from rapid imbibition, to maximize water collection.

Another group of epiphytes, Tillandsia species (belonging to the Bromeliaceae), show external absorptive scales which form a "capillary coat" covering the leaf surface. Upon wetting, the water is absorbed by the base of these scales as well as efficiently conducted along the surface within this "capillary coat", as recently also demonstrated by [19]. In both groups of epiphytes, a tissue therefore evolved via convergent evolution which is capable of both absorbing and distributing water.

The main difference between the scale coat of Tillandsia leaves and the velamen radicum of aerial orchid roots is, however, the circumstance that the former are able to actively control evaporation, in contrast to the latter. Therefore, it is entirely to be expected that reducing evaporation is an additional functional aspect of the velamen radicum.

In this context, the finding that both rates of imbibition and evaporation depend on the ratio $\tau^{2} \phi / \phi_{\mathrm{a}}$ is instructive: both increase with this ratio. Swift imbibition means also rapid evaporation, implying a trade-off problem. The velamen radicum represents therefore an exemplary material which integrates different-and partially antagonistic-tasks.

The experimental observations indicate that quite substantial differences exist between species, consistent with the differences in velamen structure. These differences were distinct despite a large data scatter, as is common for biological systems. Also consistent with experimental observations were the theoretical results obtained in this contribution and which were based on the anatomical data. The large differences between species probably reflect different demands and strategies, according to different ecological niches and environments.

For example, species living in the shady interior of a moist forest experience possibly less pressure with respect to water harvest. Another-quite interesting-aspect is that various species have no leaves and rely on their aerial roots for photosynthesis, as is the case for M. exilis. Here, a thick velamen filled with water represents an obstacle to gas exchange for photosynthesis. Hence, such leafless orchids show a thin velamen. Also, living passage cells represent a bottleneck with respect to the final step of water absorption into the living root interior. Maximizing imbibition velocity of the velamen radicum would have no effect for the velocity of the entire process of water uptake if passage cells are slow to absorb the stored water. Increasing the density of passage cells means, however, increasing potential evaporative sites. Protecting passage cells by a patch of denser material might be an appropriate means to reduce evaporation out of the cortex.

There are very probably various traits of the velamen radicum which represent a kind of fine-tuning to meet the special ecophysiological demands of the different species. For example, the data collected in this study indicate that the velamen cell-wall porosity $\phi_{a}$ (and thus, the permeability $k$, according to (15)) of the innermost cell layer of the velamen exceeds, for most species, the porosity of the other layers by roughly $10 \%$. Water may therefore preferentially be conducted to the innermost layers, into the vicinity of the passage cells. With the theoretical framework applied in this study, it was not possible to study this effect in detail. To unravel possible form-function relationships more deeply, other methods are necessary, such as numerical approaches which would also allow to model the effect of passage cell density. Also, the intricate structures above the passage cells appear to merit further consideration. All in all, the results of this study support the notion of the velamen radicum as an interesting biomaterial.

Acknowledgements F.H. would like to thank Andreas Franzke, Simone Elfner, and Anette Mülbaier (Botanical Garden of the University of Heidelberg), Brigitte Fiebig, Oliver König and Andreas Binder (Botanical Garden of the University of Tübingen), and Oliver Zimmer, Bernd Uhlmann, and Björn Schäfer (Botanical Garden at the Wilhelma, Stuttgart) for providing study plants and for helpful advice in handling them. Furthermore, we thank Hartmut Schulz (University of Tübingen) for his support with the SEM equipment.

Funding Open Access funding enabled and organized by Projekt DEAL.

\section{Compliance with ethical standards}

Conflict of interest The authors declare that they have no conflict of interest. 


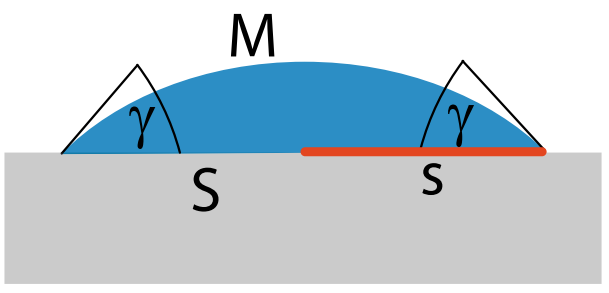

Fig. 8 Water droplet (blue) on a solid substrate (grey). $\gamma$ denotes the (macroscopic) contact angle; $s$ (red) is the radius of the contact area $S$ between droplet and substrate. The interface between droplet and air (of area $M$ ) is treated as a section of a sphere with radius

Open Access This article is licensed under a Creative Commons Attribution 4.0 International License, which permits use, sharing, adaptation, distribution and reproduction in any medium or format, as long as you give appropriate credit to the original author(s) and the source, provide a link to the Creative Commons licence, and indicate if changes were made. The images or other third party material in this article are included in the article's Creative Commons licence, unless indicated otherwise in a credit line to the material. If material is not included in the article's Creative Commons licence and your intended use is not permitted by statutory regulation or exceeds the permitted use, you will need to obtain permission directly from the copyright holder. To view a copy of this licence, visit http://creativecommons.org/licenses/by/4.0/.

Table 1 Numerical input values used in the calculations

\begin{tabular}{|c|c|c|c|}
\hline & & D. nobile & M. exilis \\
\hline Radius of aerial root $[\mu \mathrm{m}]$ & $r_{\mathrm{a}}$ & 625 & 499 \\
\hline Thickness of velamen $[\mu \mathrm{m}]$ & $Z$ & 390 & 37 \\
\hline Porosity of the velamen $^{a}[-]$ & $\phi$ & 0.91 & 0.83 \\
\hline Cell volume $\left[10^{3} \mu \mathrm{m}^{3}\right]$ & $V_{\mathrm{c}}$ & 195 & 30 \\
\hline Cell $\operatorname{radius}^{b}[\mu \mathrm{m}]$ & $q$ & 36 & 19 \\
\hline Area of wall pores $\left[\mu \mathrm{m}^{2}\right]$ & $A_{a}$ & 47 & 3 \\
\hline Cell-wall porosity [-] & $\phi_{\mathrm{a}}$ & 0.08 & 0.04 \\
\hline Thickness of cell wall $[\mu \mathrm{m}]$ & $d$ & 1.2 & 1.3 \\
\hline Contact angle & $\theta$ & $76^{\circ}$ & $85^{\circ}$ \\
\hline Droplet volume $\left[\mathrm{mm}^{3}\right]$ & $V$ & 9.3 & 9.3 \\
\hline Radius of contact line [mm] & $R_{0}$ & 1.9 & 1.9 \\
\hline Thickness of water disc $[\mu \mathrm{m}]$ & $H$ & 97 & 37 \\
\hline Observed absorption time [s] & $t_{\mathrm{obs}}$ & 45 & 507 \\
\hline Range of $t_{\mathrm{obs}}[\mathrm{s}]$ & & $(5-155)$ & $(55-2385)$ \\
\hline Calculated absorption time [s] & $t_{\text {calc }}$ & $24 \mathrm{c}$ & $4979 \mathrm{c}$ \\
\hline Surface tension of water $[\mathrm{mN} / \mathrm{m}]$ & $\sigma$ & 72.75 & \\
\hline Viscosity of water $[\mathrm{mPa}$ s] & $\mu$ & 1.0016 & \\
\hline
\end{tabular}

${ }^{\mathrm{a}}$ The porosity of the velamen has not been measured, but calculated from measured values of cell volume, thickness of cell wall, and cellwall porosity, and from estimated elongation of the cells. For details, see Appendix 3

${ }^{\mathrm{b}}$ In view of the mean capillary pressure (6), cell radius $q$ is defined as the radius of a sphere with cell volume $V_{\mathrm{c}}$; that is, $q=\sqrt[3]{3 V_{\mathrm{c}} /(4 \pi)}$

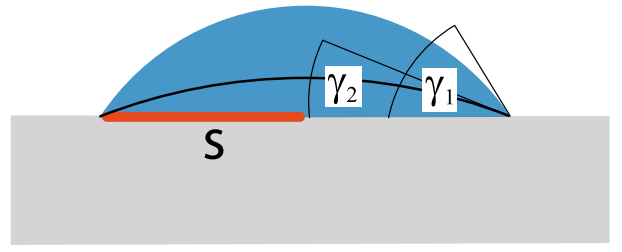

$R=s / \sin \gamma$. Due to the pinning, the loss of water molecules caused by evaporation induces the (macroscopic) contact angle $\gamma$ to decrease $\left(\gamma_{1} \rightarrow \gamma_{2} \ldots \rightarrow 0\right)$, whereas the radius $s$ of the contact area $S$ remains constant

\section{A simple model of droplet evaporation}

Water molecules evaporate from the surface of the droplet into the surrounding air, building up a humidity gradient that points away from the droplet and gives rise to a diffusional current of water molecules. This process obeys the balance equation:

$-I \mathrm{~d} t=\mathrm{d} N=\frac{\mathrm{d} V}{V_{\mathrm{m}}}$

that is, during the time interval $\mathrm{d} t$, the diffusion current $I$ carries away $\mathrm{d} N$ water molecules; the droplet volume $V$ decreases, thereby by the amount $\mathrm{d} V\left(V_{\mathrm{m}}\right.$ denotes the molar volume of liquid water).

For what follows (i) we assume stationary conditions, (ii) we ignore thermodynamic effects, such as droplet cooling caused by evaporation, and (iii) we assume that the droplet can approximately be described as a spherical calotte (Fig. 8). If the contact angle $\gamma$ and the radius $s$ of the circular contact line are given, the droplet's shape is completely described and its volume $(V)$ and its contact areas with substrate $(S)$ and air $(M)$ can be expressed as:

$V=\frac{\pi s^{3}}{3} \frac{(1-\cos \gamma)^{2}(2+\cos \gamma)}{\sin ^{3} \gamma}$

$S=\pi s^{2}$

$M=\frac{2 \pi s^{2}}{1+\cos \gamma}$.

For droplets that are pinned to their substrate, the contact area radius $s$ remains unchanged during their evaporation. The shrinkage of their volume is indicated by a steady decrease of the contact angle $\gamma$ which is finished when $\gamma=0$ (implying $V=0$, according to expression (25)).

To exploit Eq. (24), we need an explicit expression for the diffusional current $I$. Starting point is the diffusion equation $\Delta w=0$ whose solution (plus appropriate boundary and initial 


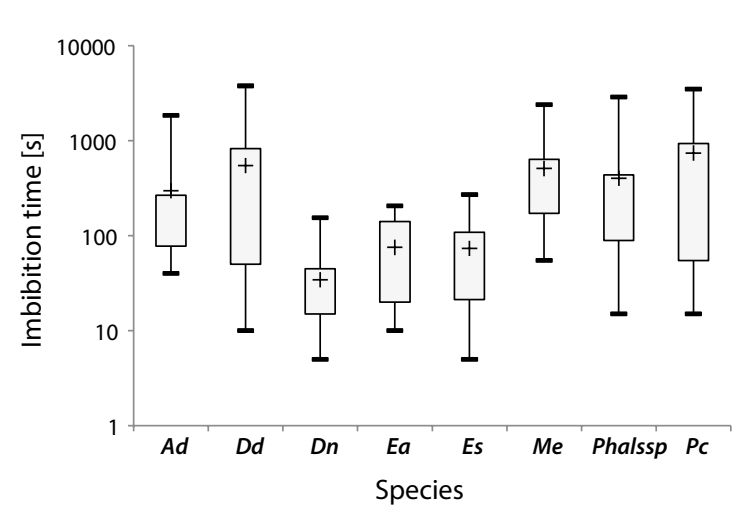

Fig. 9 Left: Imbibition times into the velamen for a droplet of volume $V=9.3 \mathrm{~mm}^{3}$ for various species (see species list in Fig. 4). The velamen was dry when the droplets were placed. Right: Drying times

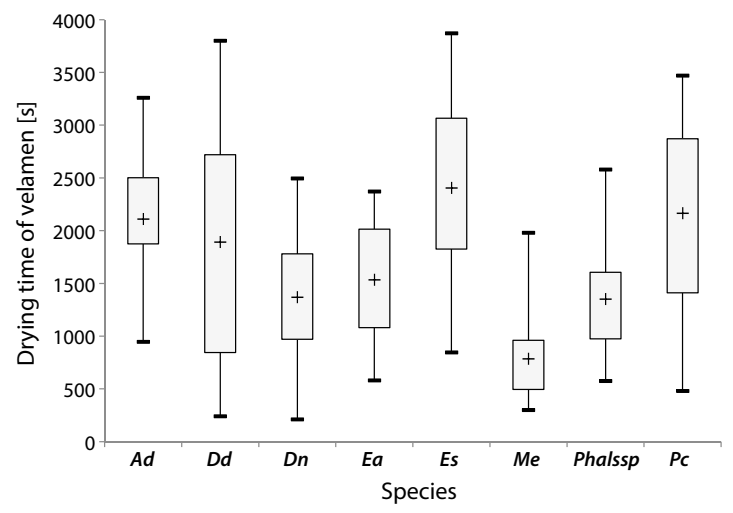

of the velamen after complete imbibition of a droplet of volume $V=9.3 \mathrm{~mm}^{3}$ for various species
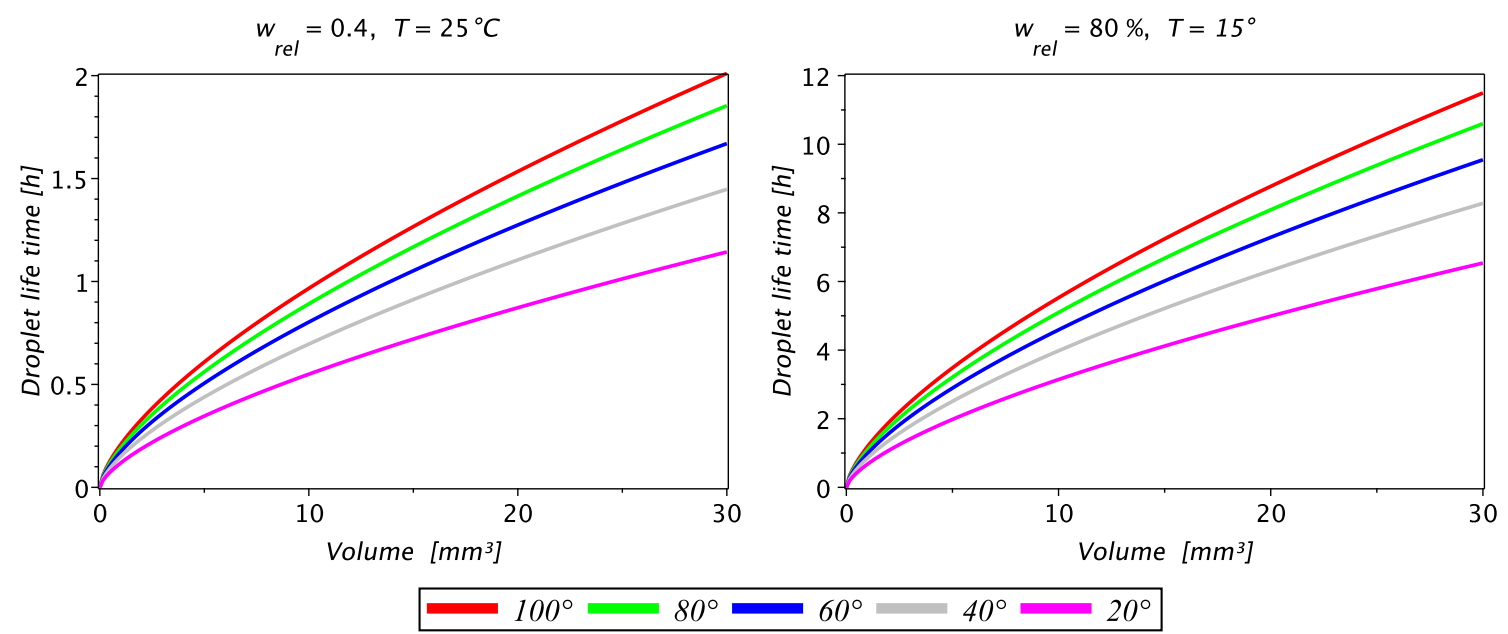

Fig. 10 Life time of a droplet until complete evaporation, calculated as a function of droplet volume, from expression (1). The different curves are related to different values of the (initial) macroscopic con-

tact angle $\gamma_{0}$. Relative humidity $w_{\text {rel }}$ and temperature $T$ attain different values in the subfigures

conditions) describes the concentration $w$ of the evaporated water molecules. We use spherical polar coordinates $(r, \theta, \varphi)$. The axial symmetry of the situation allows to orient the coordinate system conveniently in such a way that the concentration depends only on $r$ and $\theta$. Assuming furthermore stationary conditions, the diffusion equation reduces to:

$\Delta w(r, \theta)=\frac{1}{r^{2}} \frac{\partial}{\partial r}\left(r^{2} \frac{\partial w}{\partial r}\right)+\frac{1}{r^{2} \sin \theta} \frac{\partial}{\partial \theta}\left(\sin \theta \frac{\partial w}{\partial \theta}\right)=0$.

In case the contact angle attains the special value $\gamma=\pi / 2$, the interface $M$ between water and air coincides with a coordinate surface defined by $r=r_{\mathrm{i}}$. In this case, $w(r, \theta)$ does not depend on $\theta$ and (28) has the simple solution:

$w(r)=\frac{a}{r}+b$,

with integration constants $a$ and $b$. Imposing the boundary conditions:

$\lim _{r \rightarrow \infty} w(r)=w_{\mathrm{a}} \quad$ and $\quad w\left(r_{\mathrm{i}}\right)=w_{\mathrm{i}}$,

one finds:

$a=\left(w_{\mathrm{i}}-w_{\mathrm{a}}\right) r_{\mathrm{i}} \quad$ and $\quad b=w_{\mathrm{a}}$,

where $w_{\mathrm{i}}$ and $w_{\mathrm{a}}$ denote the humidities at the water/air interface at $r=r_{\mathrm{i}}$ and at infinity, respectively. Insertion of (31) into (29) implies for the current density $j(r)=-D \operatorname{grad} w(r)$ : 


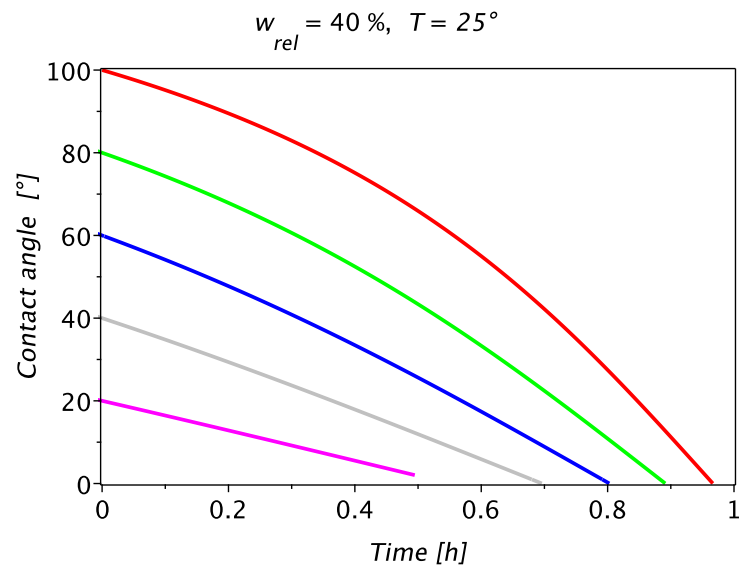

Fig. 11 Temporal evolution of the decrease of droplet volume due to vaporization, calculated from expression (40). The droplet is supposed to be placed on the surface of the velamen (droplet volume at time $t=0$ is $V=9.3 \mathrm{~mm}^{3}$ ). The different curves within each subfigure are related to the initial contact angle $\gamma_{0}$ at $t=0$, indicated by

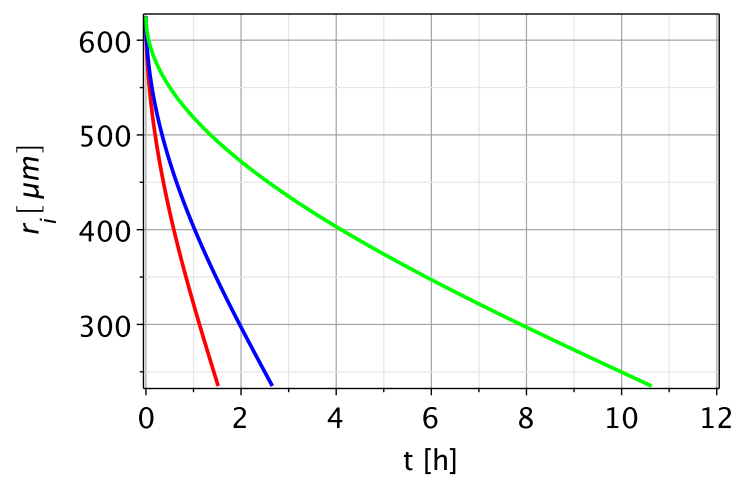

Fig. 12 Position of the water/air interface $r_{\mathrm{i}}(t)$ according to relation (14) for the three values $w_{\text {rel }}=(30 \%, 60 \%, 90 \%)$ (red, blue, green) of atmospheric humidity. At $t=0$, when evaporation starts, the velamen is supposed to be soaked with water up to the radius $r_{0}=r_{\mathrm{a}}$. Evapora-

$j(r)=\frac{D\left(w_{\mathrm{i}}-w_{\mathrm{a}}\right) r_{\mathrm{i}}}{r^{2}}$,

where $D$ is the coefficient of diffusion of water vapor in air (at $T=25^{\circ} \mathrm{C}$ holds $D=2.6 \times 10^{-5} \mathrm{~m}^{2} / \mathrm{s}$ ). The total current $I$ follows via integration over the surface of a half sphere with radius $r=$ const.:

$I=\int_{\theta=0}^{\pi / 2} \int_{\varphi=0}^{2 \pi} j(r) r^{2} \mathrm{~d} \varphi \mathrm{d} \theta=2 \pi D\left(w_{\mathrm{i}}-w_{\mathrm{a}}\right) r_{\mathrm{i}}$.

In the generic case, i.e., if $\gamma \neq \pi / 2$ applies and the interface $M$ does not coincide with a coordinate surface $r=r_{\mathrm{i}}$, expressions (29) and (32) show an intricate dependency on $\theta$. To keep things simple, we stick to expressions (29) and (32) as

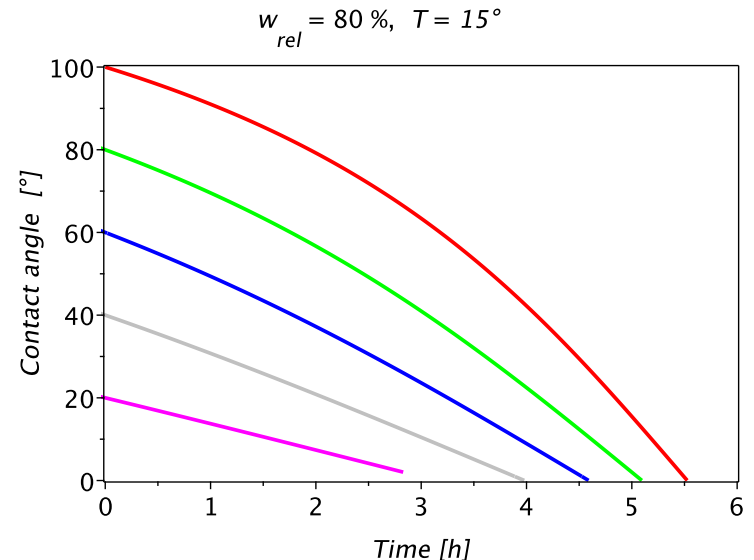

the intersection points of these curves with the ordinate axis. Once the droplet has been completely vaporized, the contact angle has decreased to zero and the curves intersect the abscissa, indicating the droplet life time. Relative humidity $w_{\text {rel }}$ and temperature $T$ attain different values in the subfigures

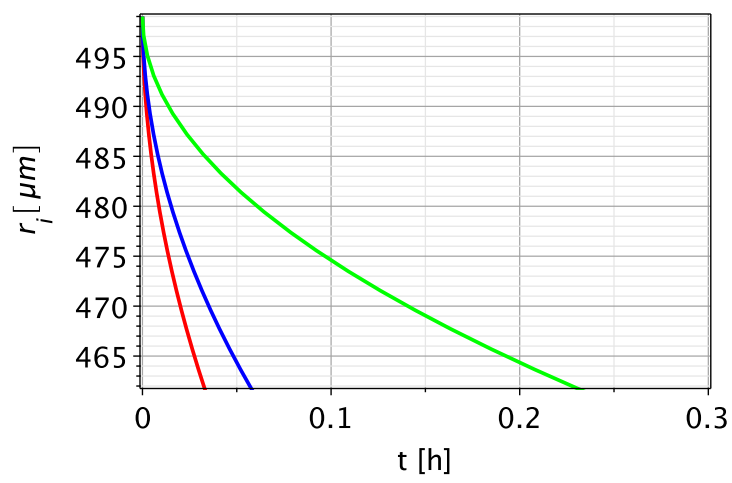

tion stops when the water/air interface at $r_{i}(t)$ has receded to the exodermis, located at $r=r_{\text {a }}-Z$. Left: Calculation for $D$. nobile. Right: Calculation for $M$. exilis. Input values: $T=20^{\circ} \mathrm{C}$ and Table 1

they stand, even if $\gamma \neq \pi / 2$, but approximate the real interface $M$ by a fictitious coordinate surface $r=r_{\mathrm{i}}$ of the same area, that is, we require (see (27)):

$\frac{2 \pi s^{2}}{1+\cos \gamma}=2 \pi r_{i}^{2}$

which implies that:

$r_{\mathrm{i}}=\frac{s}{\sqrt{1+\cos \gamma}}$

and, for the current (33):

$I=\frac{2 \pi D\left(w_{\mathrm{i}}-w_{\mathrm{a}}\right) s}{\sqrt{1+\cos \gamma}}$. 
Rewriting Eq. (24) in the form:

$-I=\frac{1}{V_{m}} \frac{\mathrm{d} V}{\mathrm{~d} \gamma} \frac{\mathrm{d} \gamma}{\mathrm{d} t}$

exploiting (25), and using (36) leads to a non-linear ordinary first-order differential equation for $\gamma(t)$ :

$-\frac{2 \pi D\left(w_{s a t}-w_{\mathrm{a}}\right) s}{\sqrt{1+\cos \gamma}}=\frac{\pi s^{3}}{V_{m}(1+\cos \gamma)^{2}} \frac{\mathrm{d} \gamma}{\mathrm{d} t}$.

Separation of variables

$-\frac{2 D V_{\mathrm{m}}\left(w_{\mathrm{sat}}-w_{\mathrm{a}}\right)}{s^{2}} \mathrm{~d} t=(1+\cos \gamma)^{-3 / 2} \mathrm{~d} \gamma$,

and subsequent integration-imposing the initial condition $\gamma=\gamma_{0}$ at $t=0$-produces:

$$
\begin{aligned}
& \operatorname{artanh}(\sin (\gamma / 2))+\frac{\sin (\gamma / 2)}{\cos ^{2}(\gamma / 2)} \\
& \quad=\operatorname{artanh}\left(\sin \left(\gamma_{0} / 2\right)\right)+\frac{\sin \left(\gamma_{0} / 2\right)}{\cos ^{2}\left(\gamma_{0} / 2\right)}-\frac{4 \sqrt{2} D V_{\mathrm{m}}\left(w_{\text {sat }}-w_{\mathrm{a}}\right)}{s^{2}} t .
\end{aligned}
$$

This expression describes how the (macroscopic) contact angle $\gamma$ of a droplet of initial volume

$V_{0}=\frac{\pi s^{3}}{3} \frac{\left(1-\cos \gamma_{0}\right)^{2}\left(2+\cos \gamma_{0}\right)}{\sin ^{3} \gamma_{0}}$

that is pinned to the surface of the velamen (implying that the contact area $S=\pi s^{2}$ remains constant) decreases with time from its initial value $\gamma=\gamma_{0}$ to the value $\gamma=0$. Figure 11 illustrates this result.

The life time $t$ of the droplet (Fig. 10) follows by solving expression (40) for $t$ and letting $\gamma \rightarrow 0$, resulting in Eq. (1):

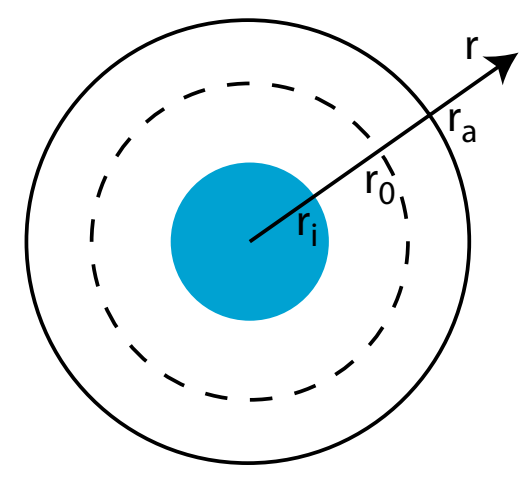

Fig. 13 Schematic cross section through the velamen. $r_{\mathrm{a}}$ : outer fringe, $r_{0}$ : position of water/air interface at beginning of evaporation, $r_{\mathrm{i}}(t)$ : instantaneous position of water/air interface

$$
t=\frac{s^{2}}{4 \sqrt{2} D V_{\mathrm{m}}\left(w_{\text {sat }}-w_{\mathrm{a}}\right)}\left[\operatorname{artanh}\left(\sin \left(\gamma_{0} / 2\right)\right)+\frac{\sin \left(\gamma_{0} / 2\right)}{\cos ^{2}\left(\gamma_{0} / 2\right)}\right] .(1)
$$

\section{Water loss in the velamen due to diffusion of water vapor}

We consider an (approximately) axially symmetric and ringlike section of the velamen of outer radius $r_{\mathrm{a}}$ and length $L$ (measured along the symmetry axis, Fig. 13). This section is supposed to be soaked with water, from the exodermis up to the water/air interface at radius $r_{\mathrm{i}}$. There, the water vaporises and the vapor diffuses along the humidity gradient through the porous velamen towards the atmosphere where humidity is usually lower than within the velamen. As a result, the water/ air interface at $r_{\mathrm{i}}$ retreats towards the exodermis. Our goal is to calculate the function $r_{\mathrm{i}}(t)$. To keep things simple, we assume that the diffusion current $I$ is directed radially. This assumption is justified near the central meridian of the section, deviations occur towards the margins of the ring.

Starting point is, as in Appendix 1, the water balance Eq. (24). The axial symmetry of the situation implies that:

$-I\left(r_{i}\right)=\frac{2 \pi r_{\mathrm{i}} L \phi}{V_{\mathrm{m}}} \frac{\mathrm{d} r_{\mathrm{i}}}{\mathrm{d} t}$.

Similarly as above, the diffusional current has to be calculated from an appropriate solution of the diffusion equation $\Delta w=0$ which reads in plane polar coordinates $(r, z, \varphi)$ :

$\Delta w(r, z, \varphi)=\frac{1}{r} \frac{\partial}{\partial r}\left(r \frac{\partial w}{\partial r}\right)+\frac{\partial^{2} w}{\partial z^{2}}+\frac{1}{r^{2}} \frac{\partial^{2} w}{\partial \varphi^{2}}=0$

and reduces because of our assumptions to:

$\frac{1}{r} \frac{\partial}{\partial r}\left(r \frac{\partial w}{\partial r}\right)=0$

with the solution:

$w(r)=a \ln (r)+b$.

The arbitrary constants $a$ and $b$ are calculated by means of the boundary conditions:

$w_{\mathrm{a}}=a \ln \left(r_{\mathrm{a}}\right)+b$

$w_{\mathrm{i}}=a \ln \left(r_{\mathrm{i}}\right)+b$,

with $w_{\mathrm{a}}=w\left(r_{\mathrm{a}}\right)$ and $w_{\mathrm{i}}=w\left(r_{\mathrm{i}}\right)$ denoting the humidities just outside the velamen and directly above the water/air interface, respectively. Insertion into (45) produces:

$$
w(r)=\frac{w_{\mathrm{a}}-w_{\mathrm{i}}}{\ln \left(r_{\mathrm{a}}\right)-\ln \left(r_{\mathrm{i}}\right)} \ln (r)+\frac{w_{\mathrm{i}} \ln \left(r_{\mathrm{a}}\right)-w_{\mathrm{a}} \ln \left(r_{\mathrm{i}}\right)}{\ln \left(r_{\mathrm{a}}\right)-\ln \left(r_{\mathrm{i}}\right)} .
$$


The current density $j(r)$ reads then:

$j(r)=-D_{\mathrm{e}} \frac{\partial w}{\partial r}=-\frac{D_{\mathrm{e}}\left(w_{\mathrm{a}}-w_{\mathrm{i}}\right)}{\left[\ln \left(r_{\mathrm{a}}\right)-\ln \left(r_{\mathrm{i}}\right)\right] r}$,

where $D_{\mathrm{e}}$ is the effective coefficient of diffusion of water vapor in the air-filled pores. The current $I$ is found by integration of $j$ over a surface defined by $r=$ const. located between $r_{\mathrm{i}}$ and $r_{\mathrm{a}}$ :

$$
\begin{aligned}
I= & \int_{z=0}^{L} \int_{\varphi=0}^{2 \pi} j(r) r \mathrm{~d} \varphi \mathrm{d} z= \\
& -L \int_{\varphi=0}^{2 \pi} \frac{D_{\mathrm{e}}\left(w_{\mathrm{a}}-w_{\mathrm{i}}\right)}{\left[\ln \left(r_{\mathrm{a}}\right)-\ln \left(r_{\mathrm{i}}\right)\right] r} r \mathrm{~d} \varphi=-\frac{2 \pi L D_{\mathrm{e}}\left(w_{\mathrm{a}}-w_{\mathrm{i}}\right)}{\left[\ln \left(r_{\mathrm{a}}\right)-\ln \left(r_{\mathrm{i}}\right)\right]} .
\end{aligned}
$$

Notice that $I$ does not depend on $r$ but on $r_{i}$, i.e., the location of the water/air interface. Insertion of (50) into (42) produces:

$-\frac{D_{\mathrm{e}}\left(w_{\mathrm{a}}-w_{\mathrm{i}}\right)}{\left[\ln \left(r_{\mathrm{a}}\right)-\ln \left(r_{\mathrm{i}}\right)\right]}=\frac{\phi r_{i}}{V_{\mathrm{m}}} \frac{\mathrm{d} r_{\mathrm{i}}}{\mathrm{d} t}$

an ordinary, non-linear differential equation of first order for $r_{\mathrm{i}}(t)$ that can be solved via separation of variables. Prescribing the initial condition $r_{\mathrm{i}}=r_{0}$ at $t=0$ (Fig. 13) and noticing that directly above the water/air interface at $r_{\mathrm{i}}$, air is saturated with humidity; that is $w_{\mathrm{i}}=w_{\text {sat }}$, one arrives after a few manipulations at:

$$
\begin{aligned}
t= & \frac{\tau^{2} \phi}{4 V_{\mathrm{m}} D\left(w_{\mathrm{sat}}-w_{\mathrm{a}}\right) \phi_{\mathrm{a}}} \\
& \times\left(r_{0}^{2}\left[\ln \left(r_{\mathrm{a}}^{2}\right)-\ln \left(r_{0}^{2}\right)+1\right]-r_{i}^{2}\left[\ln \left(r_{a}^{2}\right)-\ln \left(r_{i}^{2}\right)+1\right]\right) .
\end{aligned}
$$

This is the time it takes the water/air interface to move from its initial position $r_{0}$ at $t=0$ to $r_{\mathrm{i}}$. (Notice that it is not possible to solve (14) explicitly for $\left.r_{\mathrm{i}}(t)\right)$. $D_{\mathrm{e}}$, the effective coefficient of diffusion in porous media is discussed in Sect. 3.5. The structure of (14)) implies that the time span $t$ required for the complete evaporation of the imbibed water depends strongly on the atmospheric humidity $w_{\mathrm{a}}$ (or rather on the difference $w_{\text {sat }}-w_{\mathrm{a}}$. Figure 12 illustrates (14) for different atmospheric humidities $w_{\text {rel }}$.

\section{Calculation of the porosity of the velamen}

The cell is approximated as a prolate spheroid with long and short half axes $C$ and $B$, respectively. The porosity of the velamen is calculated from the following quantities that have been estimated from SEM photographs: the volume $V_{\mathrm{c}}$ of the inner, void part of the cell, the thickness $d$ of the cell wall, the cell-wall porosity $\phi_{\mathrm{a}}$, and the elongation $\xi:=C / B$ of the cells. Denoting the surface of the spheroid by $A_{\mathrm{c}}$ and using the observation that the cell-wall thickness $d$ is small compared with the half axes $C$ and $B$, the total volume of the cell wall $A_{\mathrm{c}} d$ is divided into a fraction occupied by wall material, $\left(1-\phi_{\mathrm{a}}\right) A_{\mathrm{c}} d$, and a fraction occupied by wall pores, $\phi_{\mathrm{a}} A_{\mathrm{c}} d$.

Porosity is defined as the ratio of the void volume parts to the total volume, that is:

$\phi=\frac{V_{\mathrm{c}}+\phi_{\mathrm{a}} A_{\mathrm{c}} d}{V_{\mathrm{c}}+A_{\mathrm{c}} d}$.

The surface of a prolate spheroid is given as:

$A_{\mathrm{c}}=\frac{2 \pi B^{2}\left[\xi^{2} \arcsin \left(\frac{\sqrt{\xi^{2}-1}}{\xi}\right)+\sqrt{\xi^{2}-1}\right]}{\sqrt{\xi^{2}-1}}$.

The (unknown) half axis $B$ can be eliminated in favour of the (known) volume $V_{\mathrm{c}}$ employing the relation for the volume of a prolate spheroid:

$V_{\mathrm{c}}=\frac{4 \pi B^{2} C}{3}=\frac{4 \pi \xi B^{3}}{3}$.

Using (53) and (54) in (52), one obtains finally:

$\phi=\frac{\sqrt[3]{2 V_{c} \xi^{2}}+\phi_{a} \sqrt[3]{9 \pi}\left[\xi^{2} \arcsin \left(\frac{\sqrt{\xi^{2}-1}}{\xi}\right)+\sqrt{\xi^{2}-1}\right] d}{\sqrt[3]{2 V_{\mathrm{c}} \xi^{2}}+\sqrt[3]{9 \pi}\left[\xi^{2} \arcsin \left(\frac{\sqrt{\xi^{2}-1}}{\xi}\right)+\sqrt{\xi^{2}-1}\right] d}$.

Employing the elongations $\xi=1.5$ for $D$. nobile and $\xi=1.05$ for the more roundish cells of $M$. exilis produces the numeric results for $\phi$ given in Table 1 .

\section{References}

1. T. Gambaryan-Roisman, Curr. Opin. Colloid Interface Sci. 19(4), 320 (2014). https://doi.org/10.1016/j.cocis.2014.09.001

2. D. Camuffo, Water. Air Soil Pollut. 21(1-4), 151 (1984)

3. G. Zotz, U. Winkler, Oecologia 171(3), 733 (2013). https://doi. org/10.1007/s00442-012-2575-6

4. W. Barthlott, I. Capesius, Berichte der Deutschen Botanischen Gesellschaft 88(3), 379 (1975)

5. D.H. Benzing, W.E. Friedman, G. Peterson, A. Renfrow, Am. J. Bot. 70(1), 121 (1983)

6. A.M. Pridgeon, W.L. Stern, D.H. Benzing, Am. J. Bot. 70(9), 1365 (1983)

7. C.J. Goh, M. Kluge, Vascular Plants as Epiphytes (Springer, Berlin, 1989), pp. 139-166

8. T.A.C. Joca, D.C. de Oliveira, G. Zotz, U. Winkler, A.S.F.P. Moreira, Flora 230, 66 (2017)

9. M.M. Kohonen, A. Helland, J. Bionic Eng. 6(4), 324 (2009)

10. J. Bico, U. Thiele, D. Quéré, Colloids Surf. A 206, 41 (2002)

11. J. Hyväluoma, P. Raiskinmäki, A. Jäsberg, A. Koponen, M. Kataja, J. Timonen, Phys. Rev. E 73, 3 (2006). https://doi. org/10.1103/physreve.73.036705 
12. M. Sahimi, Flow and Transport in Porous Media and Fractured Rock: from Classical Methods to Modern Approaches (Wiley$\mathrm{VCH}$, Weinheim, 2011)

13. A. Scheidegger, The Physics of Flow Through Porous Media (University of Toronto Press, Toronto, 1974)

14. G.P. Partridge, D.M. Lehman, R.S. Huebner, J. Air Waste Manage Assoc. 49(4), 412 (1999). https://doi.org/10.1080/10473 289.1999 .10463812

15. F.R. Troeh, J.D. Jabro, D. Kirkham, Geoderma 27(3), 239 (1982). https://doi.org/10.1016/0016-7061(82)90033-7

16. N. Nishiyama, T. Yokoyama, J. Geophys. Res. Solid Earth 122(9), 6955 (2017). https://doi.org/10.1002/2016jb013793
17. A. Clarke, T.D. Blake, K. Carruthers, A. Woodward, Langmuir 18(8), 2980 (2002)

18. E. Bormashenko, Wetting of Real Surfaces (De Gruyter, Berlin, 2013)

19. W.B. Herppich, C.E. Martin, C. Tötzke, I. Manke, N. Kardjilov, Plant. Cell Environ. 42(5), 1645 (2019)

Publisher's Note Springer Nature remains neutral with regard to jurisdictional claims in published maps and institutional affiliations. 